\section{AB0062 PATIENTS? WILLINGNESS TO ACCEPT IMMEDIATE RISK OF DEATH IN THE TREATMENT OF RA WITH HIGH DOSE CHEMOTHERAPY}

${ }^{1} \mathrm{RJ}$ Verburg, 'SD Mahabali, ${ }^{2} \mathrm{JK}$ Sont, ${ }^{2} \mathrm{AM}$ Stiggelbout, ${ }^{1} \mathrm{JM}$ Van Laar. ${ }^{1}$ Rheumatology; ${ }^{2}$ Medical Decision Making, Leiden University Medical Center, Leiden, The Netherlands

\subsection{6/annrheumdis-2001.1123}

Background Patients with intractable rheumatoid arthritis (RA) may benefit from treatment with high dose chemotherapy (HDC) followed by rescue with autologous peripheral blood stem cells (SCT). The aim of this study was to establish whether the risks of this approach are acceptable to patients with RA and whether risk taking was associated with disease associated, socioeconomic parameters and/or personality.

\section{Objectives}

Methods 45 RA patients with active RA enrolled. Patients received information about the potential benefit of HDC (2/3 of patients good clinical response, 1/3 not), observed toxicities (alopecia, infections and bleedings) and duration of hospitalisation. Cure was assumed not te be a realistic perspective. Patients were asked what the minimal duration of benefit should be, given a transplant related mortality (TRM) of $0.01 \%$ and $2 \%$. Furthermore maximal accepted TRM was asked given a duration of benefit of 2 years. Analysis of predictive factors of patients? willingness to accept risk of death by the Mann-Whitney U-test was performed with parameters of disease activity (Swollen Joint Count, Tender Joint Count, VAS, ESR and HAQ), socio-economic parameters, RAQoL and the Life Orientation Test.

Results Of the 45 patients, 5 patients were willing to accept TRM in the treatment of RA, 40 patients were not. Of these 5 patients the mean duration of benefit given a TRM of $0.01 \%$

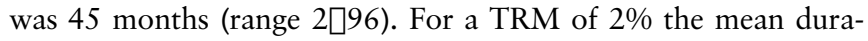

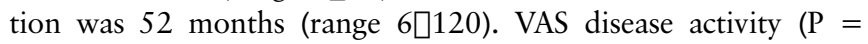
0.006), VAS pain $(P=0.021)$ and HAQ $(P=0.05)$ were signicantly higher in these patients. Religiosity $(\mathrm{P}=0.093)$ and a higher Ritchie articular index $(\mathrm{P}=0.1)$ showed a trend towards risk taking.

Conclusion We considered an approach to investigate risk taking in patients with RA based on a realistic perspective in which the trade off between short term risks and possible long term gain of HDC was investigated. It was found that patient with a chronic disease such as RA in which prevention of morbidity instead of mortality is the major

\section{AB0063 INTENSIVE THERAPY OF SYSTEM VARIANT JUVENILE RHEUMATOID ARTHRITIS}

TM Fomenko, GI Donov, IE Shahbazyan. Pediatrics, Moscow Sechenov Medical Academy, Moscow, Russia

\subsection{6/annrheumdis-2001.1124}

\section{Background}

Objectives Combined plasmapheresis (PP) with methotrexate was used in 39 children aged $2-15$ with severe system variant juvenile rheumatoid arthritis. Juvenile rheumatoid arthritis accomponied persistence infection and septic complication.

Methods PP was conducted every other day 5 times. After each PP followed by immunosupressants therapy (PIT) (bolus methylprednisolone, methotrexate). Total dose was at most $15 \mathrm{mg} /$ week. Then patients received injections imunoglobulines every other day 3 times. Total dose imunoglobulines was 0,4 ? 0,6 mg/ kg. 12 patients had herpes infection. Before intensive therapy patients received zovirax.

Results During first week by used intensive methods of therapy used to disappear basic indication of disease. After 2 weeks state of patients was stably and not required intensive therapy. 9 patients from 39 had remission about 12 months. These patients used intensive methods of therapy repeatedly. 12 patients had exacerbation a year later after intensive therapy. These patients received only basic therapy. 1 died 2 years after the end of the treatment. 17 patients developed complete remission in 16 ? 36 months. All these patients received basic therapy (prednisolone, methotrexate).

\section{AB0064 COMPARATIVE EVALUTION OF ORAL ENZYMES VERSUS STANDARD THERAPY IN ASPECT TO EFFICACY AND TOLERABILITY IN TREATMENT OF RHEUMATOID ARTHRITIS AND JUVENILE IDIOPHATIC ARTHRITIS}

${ }^{1} \mathrm{M}$ Zeibarts, ${ }^{1} \mathrm{I}$ Purvinsh, ${ }^{2} \mathrm{H}$ Mikazhane, ${ }^{3} \mathrm{R}$ Shantere, ${ }^{3} \mathrm{~V}$ Stanevicha, ${ }^{3} \mathrm{~A}$ Scegolevs. ${ }^{1}$ Department of Pharmacology, University Children Hospital; ${ }^{2}$ Centre of Rheumatology; ${ }^{3}$ Department of Rheumatology, University Children Hospital, Riga, Latvia

\subsection{6/annrheumdis-2001.1125}

Background Tolerability and side effects of standard therapy used in rheumatology are the most serious problem, especially if treatment must be started in early age. Gastrointestinal endoscopies allow to detect injury of gastrointestinal mucosa in up to $75 \%$ patients, who are using NSAIDs over longer period. Adjuvant treatment with omeprazol or nizoprostol raises the cost of treatment. For this purpose oral enzymes (OE) can be used in treatment of joint diseases, as they possess the properties of both basic medications and antiinflammatory drugs. Oral enzymes Phlogenzym allow to refuse from NSAIDs or to shorten the course of NSAIDs.

Objectives The goal of the present evaluation was to assess the efficacy and tolerability of Phlogenzym in treatment of joint diseases;1) versus NSAIDs, 2) versus DMARDs.

Methods We evaluated total 86 patients of both genders with first time diagnosed illness. 40 RA patients aged between 20 62 years: 20 patients got DMARDs and Phlogenzym,20 patients got DMARDs and NSAIDs. 46 JIA patients aged between $7-17$ years: 23 patients got Phlogenzym and shorter course of NSAIDs, 23 patients got standard therapy DMARDs and shorter course of NSAIDs.

Results

- after the RA patients treatment during 4 months the efficacy of combined treatment with DMARDs and OE was estimated as superior $84 \%$ versus DMARDs and NSAIDs as $75 \%$.

Integrative tolerability rate was in RA treatment as 3,8 vs. 3,6.

- after the JIA patients treatment during 3 months the efficacy of combined treatment with OE and NSAIDs was estimated as superior 70\% versus DMARDs and NSAIDs as 53\%.

Integrative tolerability rate was in JIA treatment identical.

Otherwise we obtained elimination of Helicobater pylori after adequate treatment in all 7 Helicobacter pylori (+) cases in JIA patients treated with $\mathrm{OE}$, healing of duodenal ulcer in 1 patients and healing of erosive gastritis in 3 patients. Among 5 Helicobacter pylori $(+)$ patients treated with DMARDs and NSAIDs only 1 became Helicobacter pylori (-) after same "Tripl” therapy (Amoxicillinum, Metronidazolum, Ranitidinum/Omeprazolum). Conclusion Our evaluation corresponding to the judgements given by the doctors concerning efficacy and tolerability to 
tested drugs shows that treatment with Phlogenzym was safe and more effective.

According to these results it can be stated that $\mathrm{OE}$ is the group of medicines, which may be used for substitution of DMARDs or NSAIDs considering to course of disease and concomitant pathologies.

\section{AB0065 SIDE EFFECTS OF DEPOT CORTICOSTEROID - DIPROPHOS $^{\circledR}$ IN THE LONG TERM TREATMENT OF RHEUMATOID ARTHRITIS}

DZ Stefanovic, BC Glisic, ZV Andjelkovic, MM Cirkovic, MR Petronijevic, DV Mitrovic, MM Popovic. Clinics of Rheumatology, Military Medical Academy, Belgrade, Yugoslavia

10.1136/annrheumdis-2001.1126

Background Corticosteroids are widely prescribed as potent antiinflammatory drugs, but in treatment of rheumatoid arthritis (RA) severe adverse effects often limit their benefits.

Objectives We estimated side effects of depot corticosteroid diprophos ${ }^{\circledR}$ in the long term treatment of rheumatoid arthritis. Methods During six years we followed up 185 patients from the first onset of RA. Among them, 47 have been treated with combined therapy with methotrexate and chlorochine, 36 with methotrexate and sulfasalazine, while 38,41 and 23 were on monotherapy with methotrexate, chlorochine and sulfasalazine, respectively. In all these patients, depot corticosteroid DIPROPHOS $^{\circledR}$ (betametazone - combined sodium dipropionate/phosphate salt) have been administrated in $3 \square 5$ weeks periodic intervals as one i.m. injection during minimum 6 months.

Results In most of patients (168/185 i.e. 91\%) permanent clinical and biohumoral remission with slow radiographic disease progression was obtained. At the same time, we failed to notice any metabolic and gastrointestinal side effects due to corticosteroid use. Also in long-time follow up, there was no evidence of clinically important hormonal and psychiatric impairments as well as frequent infections. Only skin and ocular adverse effects were noticed.

Conclusion Depot corticosteroids could be considered as integral effective and safe part of RA treatment.

\section{AB0066 TREATMENT OF RHEUMATOID ARTHRITIS WITH LEFLUNOMIDE}

M Castellanos, N Navarro, MC García, C Galisteo, M Sanmartí, MP Lisbona, C Alegre. Rheumatology, Hospital de Malalties Reumatiques, Barcelona, Spain

\subsection{6/annrheumdis-2001.1127}

\section{Background}

Objectives To study the clinical efficacy and safety for the treatment in patients with rheumatoid arthritis (RA) with Leflunomide.

Methods We included 15 patients with diagnostic of the RA according to American College of Rheumatology (ACR) criterias for at least 6 months and active disease by the following inclusion criteria: $>18$ years old, $>6$ tender and swollen joints, $>$ $15 \mathrm{mg} / \mathrm{dl}$ C-reactive protein (CRP), $>28 \mathrm{~mm} / \mathrm{h}$ erythrocyte sedimentation rate (ESR) and morning stiffness. We treated with Leflunomide loading dose $100 \mathrm{mg} /$ day for 3 days, and after we continued with $20 \mathrm{mg} /$ day. The clinical controls were the first and the end of a period of time, 26 weeks: general examination (weight, arterial pressure, morning stiffness), locomotor system (tender and swollen joint count score), acute- phase reactant (PCR, ESR) inmunology (ANA, anti-DNA, FR, C3, C4) hepatic serologies, simple radiography study (thorax, hands and feet). Evaluation of patients with a general pain, analogic visual (EVA) and the Stanford Healt Assessment Questionaire (HAQ). Non steroidal antiinflamatories drugs and steroids were allowed provided the subject had been receiving a continuous dose for at least 28 days prior to entry in the study. Intra-articular corticosteroid were not allowed.

Results The 15 patients 3 are men and 12 women, with a mean age of 68 years. After 3 months, the mean changes were -6.9 swollen joints, -10.4 tender joints, -44.8 for ESR, -26 for CRP. The most common adverse events with this treatment were three: one cutaneous allergic reaction (in this case was necessary stopping the treatment) and 2 diarrhoea. In one case the clinical was disappear after reducing in $10 \mathrm{mg} /$ day, and the other it should interrupt the treatment.

Conclusion Leflunomide seems to be efficacious and safety for treatment in RA. Every way, must follow evaluation for a long time to recommend treatment like a first election.

\section{AB0067 VASCULAR ENDOTHELIAL GROWTH FACTOR (VEGF) AND ITS RECEPTORS IN RHEUMATOID ARTHRITIS AND OSTEOARTHRITIS}

B Fink, A Böttcher, B Schwarloh, M Fuerst, N Hansen-Algenstaedt, W Rüther, P Algenstaedt. Orthopaedic Department and Department of Internal Medicine, UniversityHospital Hamburg-Eppendorf, Hamburg, Germany

10.1136/annrheumdis-2001.1128

Background Rheumatoid arthritis (RA) is characterised by synovial proliferation. Tissue proliferation in general is known to be dependent on sufficient oxygen and nutrition supply. Therefore angiogenesis, the process of new vessel formation, is considered to play a crucial role not only for tumour growth but also in rheumatoid arthritis. The angiogenetic process is regulated by several cytocines. Most important factor is the Vascular Endothelial Growth Factor (VEGF) and its cognate receptors KDR and FLT-1, known to be regulated by hypoxia as well as inflammatory cytocines. On the other hand RA is a chronic inflammatory process.

Objectives The aim of this study was to investigate whether the angiogentic process in RA is a local versus a systemic effect.

Methods Synovial tissue was taken during total knee replacement from 20 patients with RA and 20 patients with osteoarthritis (OA). Expression of VEGF, KDR and FLT-1 mRNA was analysed quantitatively using real-time PCR (Light-Cycler). Moreover in these patients plasma level of VEGF was examined using ELISA.

Results VEGF and FLT-1 were detected in the synovial tissue of all RA- and OA-patients. The levels were significantly higher in patients with RA compared to OA. KDR was established in $60 \%$ of RA and $25 \%$ of OA. Plasma level of VEGF was increased in $100 \%$ of the RA-patients and in $60 \%$ of the OA-patients.

Conclusion VEGF and its cognate receptors are significantly higher expressed in synovial tissue of patients with rheumatoid arthritis. Increased expression levels in patients with osteoarthritis might be due to reactive inflammatory synovitis. Therefore antiangiogenitic therapy might be useful not only in rheumatoid arthritis but also in reactive inflammatory arthritis. Significantly increased VEGF-plasma-levels in patients with rheumatoid arthritis may explain the benefit of a systemic, versus a local antiangiogentic therapy. 